\title{
SUPLEMENTAÇÃO COM ALTA DOSAGEM DE CAFEÍNA NÃO AFETA RESISTÊNCIA À FRATURA ÓSSEA EM RATAS SUBMETIDAS A TREINAMENTO DE SALTOS VERTICAIS*
}

\author{
ESP. GILTON DE JESUS GOMES \\ Especialista em exercício físico aplicado à reabilitação cardíaca pela Universidade Gama Filho (UGF) \\ (Rio de Janeiro - Brasil) \\ E-mail: tico_gomes@yahoo.com.br
}

MS. MIGUEL ARAUJO CARNEIRO-JÚNIOR

Mestre em educação física pela Universidade Federal de Viçosa (UFV)

Doutorando em ciências fisiológicas pela Universidade Federal do Espírito Santo (UFSC)

(Espírito Santo - Brasil)

E-mail:miguel.junior@ufv.br

MS. MÁRCIA FERREIRA DA SILVA

Mestre em educação física pela UFV (Minas Gerais - Brasil)

E-mail: marcisanty@yahoo.com.br

\section{DR. FREDERICO SOUZALIMA CALDONCELLI FRANCO}

Doutor em ciência e tecnologia de alimentos pela UFV

Professor do Centro Federal de Educação Tecnológica de Rio Pomba (Minas Gerais - Brasil)

E-mail: frederico.franco@ifsudestemg.edu.br

\section{DR. JOÃO CARLOS BOUZAS MARINS}

Doutor em bases fisiológicas da nutrição pela Universidad de Murcia (Espanha)

Professor do Departamento de Educação Física da UFV (Minas Gerais - Brasil)

E-mail: jcbouzas@ufv.br

\author{
DR. ANTÔNIO JOSÉ NATALI \\ Doutor em fisiologia pela University of Leeds (Inglaterra) \\ Professor do Departamento de Educação Física da Universidade Federal de Viçosa (Minas Gerais - Brasil) \\ E-mail: anatali@ufv.br
}

\section{RESUMO}

Objetivo: testar os efeitos de altas doses de cafeína na resistência óssea à fratura em ratas jovens submetidas a treinamento de saltos verticais. Métodos: ratas jovens foram alocadas em 4 grupos (Fatorial 2 × 2, Cafeína e Exercício). Grupos Cafeína receberam 3 doses ( 10

* O presente trabalho não contou com apoio financeiro de nenhuma natureza para sua realização. Não houve conflitos de interesses para realização do presente estudo. 
mg/l 00 g m.c.)/semana. Grupos Exercício realizaram treino de saltos verticais na água, 5 sessões/semana, por 6 semanas. Avaliou-se o cálcio urinário, diâmetro, massa e resistência à fratura do fêmur. Resultados: cafeína e exercício aumentaram a excreção de cálcio. Cafeína reduziu a massa femoral, mas não afetou sua resistência à fratura. Exercício aumentou o diâmetro e a resistência femoral à fratura. Conclusão: cafeína não prejudica a resistência óssea em ratas jovens enquanto saltos verticais fortalecem os ossos.

PALAVRAS-CHAVE: Exercício; saúde óssea.

\section{INTRODUÇÃO}

A cafeína é um alcaloide ( I,3,7-trimetilxantina) que se diferencia pela potente ação estimulante sobre o sistema nervoso central, acarretando um aumento na liberação de catecolaminas na corrente sanguínea (AltimARI et al., 2006a, 2006b). $\bigcirc$ uso da cafeína é bastante comum entre os atletas, que visam tanto à melhora no desempenho físico quanto ao retardo da fadiga durante o exercício (MAGKOS; KaVOURAS, 2005; VAN THUYNE et al., 2005).

Em exercícios intensos de curta duração, a cafeína atua diretamente na transmissão de estímulos na interação neuromuscular e aumenta a liberação sarcoplasmática de cálcio. (GreER et al., 1998). A cafeína aumenta também a sensibilidade dos miofilamentos ao cálcio, potencializando a produção de força muscular (HESPEL et al., 200 I; JAMES et al., 2004). Há evidências de que a cafeína aumenta o tempo até a fadiga durante a realização de exercícios de força (por ex.: Kalmar; Cafarelli, I999; SMith et al., 2005), apesar de alguns resultados em contrário (por ex.: AstORINO et al., 2008; FIMLAND et al., 20 I 0). Deve-se considerar também a ocorrência do efeito placebo da cafeína no exercício de força (por ex.: DUNCAN et al., 2009).

Em contrapartida, a ingestão de altas doses de cafeína pode aumentar a taxa de reabsorção óssea, alterar a microestrutura desse tecido e reduzir a densidade mineral óssea (DMO) em humanos e animais (HEANEY, 2002; RAPURI et al., 200 I). Uma das ações da cafeína no metabolismo ósseo é o aumento da excreção de cálcio, por meio do aumento da sua filtração renal e da diminuição da sua reabsorção pelos túbulos renais (AsHIZAWA et al., 1997; MASSEY; SUTtON, 2004). Efeitos negativos da cafeína sobre o tecido ósseo têm sido mostrados em mulheres pós-menopausadas (ZHOU et al., 2009).

Considerando as numerosas diferenças fisiológicas e anatômicas entre as espécies, estudos com ratos jovens mostram que a cafeína pode prejudicar o desenvolvimento normal do esqueleto (HuANG et al., 2002). Esse processo pode ocorrer pela redução do número de osteócitos por área de seção transversa, 
retardo do remodelamento estrutural ósseo, destruição dos osteoblastos, além da diminuição da densidade mineral óssea (DMO), do conteúdo mineral ósseo (CMO) e do conteúdo de cálcio da matriz óssea (HuANG et al., 2002; MAsSEY; Sutton, 2004). Todavia, pouco se sabe sobre as consequências desses efeitos deletérios na resistência à fratura óssea em ratas jovens.

Em contrapartida, o exercício físico é considerado um estímulo osteogênico importante para a massa óssea, pois, em resposta a carga mecânica sobre o osso, o efeito piezoelétrico aumenta a resposta osteoblástica e, consequentemente, a massa e a densidade mineral óssea (RoBLING et al., 2006). Além disso, o aumento da massa muscular em resposta ao exercício exerce maior tensão sobre a junção osteotendinosa, que resulta em maiores estímulos osteogênicos, com consequente aumento na deposição de minerais no tecido ósseo (IWAMOTO et al., 2005). Adaptações positivas do tecido ósseo a diferentes tipos de exercício têm sido observadas em ratos e ratas jovens (SHIGA et al., 2003; HondA et al., 2003; HUANG et al., 2008) e em humanos jovens de ambos os sexos (LINDEN et al., 2006; TourNIs et al., 20 I 0). Diferentes modelos de exercício (corrida em esteira, natação contínua e salto em profundidade) causam efeitos positivos sobre a resistência óssea à fratura em ratos e ratas (HUANG et al., 2003; HONDA et al., 2003; WeLCH et al., 2008), apesar de alguns resultados em contrário (BONNET et al., 2007). Todavia, os efeitos do modelo de saltos verticais realizado na água (OLIVEIRA et al., 2002) sobre a resistência óssea à fratura não são conhecidos.

Portanto, considerando que a ingestão de altas dosagens de cafeína pode aumentar a excreção urinária de cálcio e afetar negativamente o processo de remodelamento ósseo e que o exercício pode causar benefícios ao tecido ósseo, nossa hipótese é que o exercício de saltos na água pode contrapor os efeitos deletérios do consumo de altas doses de cafeína. Assim, o objetivo do presente estudo foi verificar os efeitos da suplementação com alta dosagem de cafeína sobre a resistência à fratura óssea em ratas jovens submetidas a um programa de saltos verticais na água.

\section{MATERIAL E MÉTODOS}

\section{ANIMAIS DE EXPERIMENTAÇÃO}

Quarenta ratas (Rattus norvegicus - Wistar) jovens, com idade de 45 dias e massa corporal de 129,6 \pm 13,4g (média \pm DP), foram divididas em 4 grupos ( $n=10$ por grupo): Sedentárias (S); Sedentárias + Cafeína (SC); Exercitadas (E); Exercitadas + Cafeína (EC). Os animais foram alojados em gaiolas individuais e foram 
mantidos em ambiente com temperatura média de $22^{\circ} \mathrm{C}$, fotoperíodo de 12 horas claro-escuro, receberam ração comercial (Socil ${ }^{\circledR}$ - Contagem, MG, Brasil) e água filtrada ad libitum. Foram seguidas todas as normas e cuidados para experimentação com animais, conforme o Colégio Brasileiro de Experimentação Animal (Cobea).

\section{ADMINISTRAÇÃO DE CAFEÍNA}

Os animais dos grupos SC e EC receberam uma dose $(10 \mathrm{mg} / \mathrm{l} 00 \mathrm{~g}$ de massa corporal) de cafeína (Sigma ${ }^{\circledR}$, ref. 84677) no primeiro, terceiro e quinto dias de cada semana, conforme Huang et al. (2002), durante seis semanas. A cafeína em pó era misturada à ração comercial triturada. Os animais recebiam mais alimento após constatado o consumo total da porção anterior. Essa dose representa $7 \mathrm{~g} / \mathrm{kg}$ de massa corporal, se ingerida por seres humanos com 70kg de massa corporal; portanto, é considerada alta (BRUCE et al., 2000).

\section{PROGRAMA DE EXERCÍCIO FÍSICO}

Foi utilizado um programa de saltos verticais na água, conforme descrito por Oliveira et al. (2002). Na primeira semana de experimento, os animais dos grupos E e EC foram colocados em um tanque de alvenaria azulejado (largura $60 \mathrm{~cm}$, comprimento $75 \mathrm{~cm}$ e altura $80 \mathrm{~cm})$ com água $\left(\sim 30^{\circ} \mathrm{C}\right)$, na profundidade de $15 \mathrm{~cm}$, por 30 minutos diários, para adaptação à temperatura e ao meio líquido. A partir da segunda semana, o programa de exercício consistiu em saltos verticais desde o fundo do tanque (apoio dos pés) até a superfície da água (narina fora d'água) (Figura I). A progressão da carga do exercício está na tabela I. Individualmente, as ratas realizaram os saltos dentro de tubos de PVC ( $150 \mathrm{~mm})$. A sobrecarga do exercício foi determinada por uma média da porcentagem da massa corporal adicionada por meio de esferas de chumbo a um colete de lycra, que vestia os animais. A profundidade da água foi determinada por uma média do percentual do comprimento dos animais, medido pela maior distância entre as extremidades dos membros posteriores e as narinas.

Tabela I - Dados da carga do programa de saltos verticais

\begin{tabular}{|c|c|c|c|c|}
\hline Semanas & Séries & Saltos & Carga & Profundidade da água \\
\hline 1 & 4 & 10 & Adaptação 30 min & $80 \%$ \\
\hline 2 & 4 & 10 & $20 \%-25 \%$ & $120 \%$ \\
\hline 3 & 4 & 10 & $30 \%-35 \%$ & $130 \%$ \\
\hline 4 & 4 & 10 & $40 \%$ & $140 \%$ \\
\hline 5 & 4 & 10 & $45 \%$ & $150 \%$ \\
\hline 6 & 4 & 10 & $50 \%$ & $150 \%$ \\
\hline
\end{tabular}

Carga: porcentagem da massa corporal; Profundidade da água: porcentagem do comprimento do animal. 


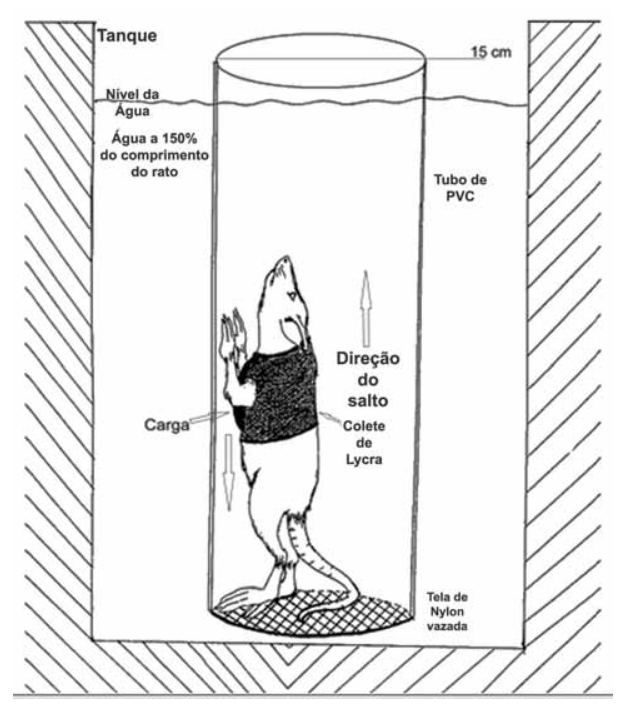

Figura: Visão esquemática do modelo de exercício.

\section{EXCREÇÃO URINÁRIA DE CÁLCIO}

Na sexta semana de estudo, as ratas foram colocadas em gaiolas metabólicas para a coleta de urina por 24 horas. $O$ volume de urina coletado foi centrifugado por I 5 minutos a 4.000rpm (Excelsa-Fanem ${ }^{\circledR}$ - Brasil), e alíquotas do sobrenadante foram utilizadas para a determinação do conteúdo de cálcio pelo método automatizado de espectrometria de UVNIS, utilizando-se kits BioClin ${ }^{\circledR}$ no equipamento ALIZÉ ${ }^{\circledR}$ (Biomêrieux ${ }^{\circledR}$ - França), conforme descrito por Henry et al. ( 1974).

\section{PARÂMETROS ÓSSEOS}

Após os tratamentos, os animais foram pesados e a eutanásia foi realizada por deslocamento cervical. $\bigcirc$ fêmur direito foi dissecado e pesado em balança de precisão (Explorer Ohaus ${ }^{\circledR}$ - Brasil). O diâmetro da diáfise óssea foi determinado no ponto intermédio do comprimento, usando-se um paquímetro inoxidável (Stainless Hardened - China).

\section{RESISTÊNCIA ÓSSEA À FRATURA}

A resistência à fratura do fêmur foi determinada por meio de um ensaio mecânico de flexão em três pontos como descrito por Nagasawa et al. (2008), Honda et al. (2003) e Tsanzi et al. (2008), usando um texturômetro (TA.HDi 
Texture Analyser - Stable Micro System Inc. - EUA). Cada extremidade do osso ficou apoiada sobre uma haste inoxidável, separadas por $2 \mathrm{~cm}$ de distância, onde uma terceira haste, apoiada sobre o ponto intermédio ósseo, realizou uma carga [carga: 0,25N; velocidade do teste: $3 \mathrm{~mm} / \mathrm{seg}$; distância: $10 \mathrm{~mm}$ ] capaz de promover a fratura óssea. A carga necessária para que o osso fraturasse e a carga de fratura relativa à massa do fêmur foram calculadas.

\section{ANÁLISE ESTATÍSTICA}

Após os dados serem submetidos ao teste de normalidade (Teste de Kolmogorov-Smirnov), aplicou-se análise de variância (ANOVA: one-way para análises de grupos e two-way para os dois fatores e suas interações). $\bigcirc$ teste de Tukey foi empregado para análise de múltipla comparação post-hoc quando necessário. Utilizou-se o software Sigma Stat versão 3.0 (SPSS) para as análises estatísticas, e o nível de significância empregado foi de $p<0,05$.

\section{RESULTADOS}

\section{MASSA CORPORAL FINAL}

O grupo EC apresentou menor massa corporal final comparada a do grupo S (Tabela 2). Os animais suplementados com cafeína (SC + EC) apresentaram redução da massa corporal em relação aos não suplementados $(S+E)$. Da mesma forma, as ratas exercitadas (E + EC) exibiram menor massa corporal final que as sedentárias $(S+S C)$.

\section{PARÂMETROS ÓSSEOS}

Os valores dos parâmetros ósseos foram normalizados em função das massas corporais e femorais. A massa do fêmur foi apresentada relativa à massa corporal (mg/g). O diâmetro da diáfise e a carga de fratura do fêmur foram apresentados relativos à massa do fêmur ( $\mathrm{mm} / \mathrm{g}$ e $\mathrm{N} / \mathrm{g}$ respectivamente). Os dados da massa corporal, o diâmetro da diáfise e a massa do fêmur estão apresentados na tabela 2.

Os animais do grupo EC exibiram menor massa corporal e maior diâmetro relativo ósseo do que os do grupo S. Para o parâmetro massa relativa do fêmur, observou-se que a do grupo E se mostrou maior que as dos grupos SC e EC, como também o grupo S foi maior do que a do SC. 
Para as análises do efeito principal dos fatores, identificou-se que os animais suplementados com cafeína apresentaram menores massas corporais e femorais, além de maior diâmetro ósseo relativo que os não suplementados. Observou-se também que as ratas exercitadas apresentaram menor massa corporal e maior diâmetro ósseo relativo, quando comparadas às sedentárias (Tabela 2). Contudo, não foi verificada interação significativa entre os fatores em nenhum desses parâmetros.

Tabela 2 - Massa corporal e parâmetros ósseos das ratas ao final do experimento

\begin{tabular}{|c|c|c|c|}
\hline Grupos & Massa corporal (g) & $\begin{array}{l}\text { Diâmetro do } \\
\text { fêmur (mm/g) }\end{array}$ & $\begin{array}{c}\text { Massa do fêmur } \\
(\mathrm{mg} / \mathrm{g})\end{array}$ \\
\hline$S(n=10)$ & $198,3 \pm 3,3$ & $|0,2| \pm 0,30$ & $1,73 \pm 0,03$ \\
\hline$S C(n=10)$ & $187,0 \pm 3,5$ & $11,46 \pm 0,43$ & $1,55 \pm 0,02 \# *$ \\
\hline$E(n=10)$ & $183,7 \pm 3,2$ & $11,02 \pm 0,23$ & $1,76 \pm 0,02$ \\
\hline$E C(n=10)$ & $174,6 \pm 4,6^{\#}$ & $12,72 \pm 0,533^{\#}$ & $1,63 \pm 0,03 *$ \\
\hline \multicolumn{4}{|c|}{ Efeito principal dos fatores } \\
\hline Cafeína (SC + EC) & $p=0,029$ & $p=0,007$ & $p<0,00$ \\
\hline Exercício $(E+E C)$ & $p=0,005$ & $p=0,021$ & $p=0,082$ \\
\hline Interação (Exercício/Cafeína) & $p=0,807$ & $p=0,730$ & $p=0,366$ \\
\hline
\end{tabular}

Os resultados estão apresentados pela média \pm EPM; \#: denota diferença estatisticamente significativa de S; *: denota diferença estatisticamente significativa de E (ANOVA one-way); efeito principal dos fatores (ANOVA two-way); S = Sedentárias; E = Exercitadas; SC = Sedentárias + Cafeína; EC = Exercitadas + Cafeína; $\mathrm{n}$ = número de animais; $\mathrm{mm} / \mathrm{g}$, diâmetro da diáfise do fêmur dividido pela massa corporal do animal; $\mathrm{mg} / \mathrm{g}=$ massa do fêmur dividida pela massa corporal do animal.

\section{EXCREÇÃO DE CÁLCIO E RESISTÊNCIA À FRATURA ÓSSEA}

Os resultados da excreção urinária de cálcio e resistência à fratura óssea relativa estão apresentados na tabela 3. Não houve diferença estatisticamente significativa na resistência à fratura óssea relativa entre os grupos. Para a excreção urinária de cálcio, observou-se que o grupo EC apresentou maior perda de cálcio que os grupos $\mathrm{SC}$ e $\mathrm{E}$.

Considerando o efeito principal dos fatores, observou-se que os animais que receberam cafeína excretaram maior conteúdo de cálcio do que os animais não suplementados. As ratas exercitadas exibiram maior resistência à fratura do fêmur do que as sedentárias (Tabela 3). 
Tabela 3 - Conteúdo de cálcio urinário e resistência do fêmur à fratura em ratas

\begin{tabular}{|l|c|c|}
\hline \multicolumn{1}{|c|}{ Grupos } & Cálcio urinário $(\mathrm{mg} / 24 \mathrm{~h})$ & Resistência à fratura (N/g) \\
\hline $\mathrm{S}(\mathrm{n}=10)$ & $3,7 \pm 0,6$ & $190,5 \pm 13,2$ \\
\hline $\mathrm{SC}(\mathrm{n}=10)$ & $3,2 \pm 0,4^{*}$ & $181,0 \pm 11,1$ \\
\hline $\mathrm{E}(\mathrm{n}=10)$ & $2,7 \pm 0,4^{*}$ & $210,2 \pm 13,3$ \\
\hline $\mathrm{EC}(\mathrm{n}=10)$ & $5,7 \pm 0,8$ & $210,7 \pm 8,6$ \\
\hline \multicolumn{3}{|c|}{ Efeito principal dos fatores } \\
\hline Cafeína (SC $+\mathrm{EC})$ & $\mathrm{p}=0,034$ & $\mathrm{p}=0,706$ \\
\hline Exercício (E + EC) & $\mathrm{p}=0,169$ & $\mathrm{p}=0,043$ \\
\hline Interação (Exercício/Cafeína) & $\mathrm{p}=0,100$ & $\mathrm{p}=0,671$ \\
\hline
\end{tabular}

Os resultados estão apresentados pela média \pm EPM; *: denota diferença estatisticamente significativa de EC (ANOVA one-way); efeito principal dos fatores (ANOVA two-way); $\mathrm{S}=$ Sedentárias; $\mathrm{E}=$ Exercitadas; $\mathrm{SC}=$ Sedentárias + Cafeína; $\mathrm{EC}=$ Exercitadas + Cafeína; $\mathrm{n}=$ número de animais; $\mathrm{mg} / 24 \mathrm{~h}$, conteúdo de cálcio urinário em 24 horas; $\mathrm{N} / \mathrm{mg}$ = resistência à fratura do fêmur dividida pela massa do fêmur.

\section{DISCUSSÃO}

O presente estudo testou a hipótese de que o exercício pode contrapor os efeitos deletérios do consumo de altas doses de cafeína sobre o tecido ósseo. Nossos dados demonstram que o consumo de altas doses de cafeína aumentou a excreção de cálcio e reduziu a massa do fêmur, sem interferir na resistência à fratura óssea em ratas jovens. O programa de saltos verticais na água, por sua vez, aumentou o diâmetro e a resistência à fratura óssea nesses animais.

Neste estudo, observou-se que a suplementação com cafeína elevou o diâmetro da diáfise femoral das ratas, independentemente do exercício. Esses resultados são similares aos encontrados por Huang et al. (2002), que utilizaram a mesma dose de cafeína em ratos. Por análise histomorfométrica da tíbia, eles verificaram que a cafeína elevou o comprimento e a espessura do platô de crescimento nas zonas de proliferação e hipertrofia, contudo, reduziu a relação volume esponjoso/volume total na tíbia proximal. Os mecanismos envolvidos nessa resposta do sistema ósseo ao consumo de alta dosagem de cafeína não estão claros. Embora no presente estudo não tenha sido analisada a interferência da cafeína sobre a secreção do hormônio de crescimento $(\mathrm{GH})$, o aumento da secreção de $\mathrm{GH}$ poderia explicar o aumento observado no diâmetro da diáfise femoral deste estudo. Todavia, apesar da secreção do $\mathrm{GH}$ promover crescimento 
de ossos longos, o efeito da cafeína na secreção de GH não é consensual (SPINDEL et al., 1980; Clozel et al., 1983; HoCHBERG et al., 1984). É possível que o aumento da secreção de GH dependa do protocolo da administração de cafeína. Assim, futuros estudos auxiliariam esclarecer se o protocolo de administração de cafeína utilizado no presente estudo aumenta a secreção de GH e o crescimento ósseo observado no presente estudo.

Em contrapartida, nossos resultados mostraram que o consumo de cafeína reduziu o peso relativo do fêmur (Tabela 2). Essa redução é coerente com nossos dados de excreção de cálcio urinário, que revelaram maior perda urinária de cálcio nas ratas suplementadas com cafeína (Tabela 3), tanto entre grupos quanto para o efeito principal dos fatores. Existem evidências de que a ingestão de altas doses de cafeína aumenta a excreção de cálcio urinário (Ashizawa et al., 1997; Massey; Sutton, 2004). A ação da cafeína pode ser explicada por alguns mecanismos, como o aumento na carga de filtração de cálcio renal e redução na reabsorção de cálcio ao nível dos túbulos proximais renais (AshizAWA et al., 1997; MASSEY; SUtTon, 2004). Portanto, sugere-se que o cálcio excretado na urina seria proveniente dos ossos dos animais, uma vez que a redução de massa óssea em resposta à ingestão de cafeína está associada à redução do conteúdo total de cálcio e da densidade mineral óssea em ratos e em humanos (HuANG et al., 2002; Dew et al., 2007; Wetmore et al., 2008). Esses achados alertam para os efeitos negativos do consumo excessivo de cafeína, inclusive na juventude.

Um achado curioso deste estudo foi observar que a resistência óssea à fratura não foi afetada pela suplementação com alta dosagem de cafeína, apesar da maior excreção urinária de cálcio, redução da massa óssea (Tabelas 2 e 3). Huang et al. (2002) observaram uma maior espessura óssea com o consumo de cafeína, contudo, não avaliaram a resistência à fratura óssea. Os resultados apresentados pelo presente estudo indicam que os efeitos negativos da ingestão de cafeína em elevar a perda de cálcio e reduzir o peso ósseo não foram suficientes para sobrepor o aumento no diâmetro da diáfise e afetar a resistência óssea nas ratas suplementadas. $\bigcirc$ aumento no diâmetro ósseo sugere um incremento em sua área de secção transversal, que poderia contrapor uma possível redução na resistência óssea acarretada pela perda de cálcio e diminuição da massa óssea. Por exemplo, estudos com humanos mostraram que o consumo excessivo de bebidas cafeinadas (400 mg cafeína/dia) não afetou a massa óssea de mulheres jovens (por ex.: WETMORE, et al., 2008). Entretanto, o consumo de bebidas cafeinadas (330 mg cafeína/dia), 
juntamente com baixa ingestão de cálcio ( $<700$ mg/dia), estava associado com o aumento no risco de fratura óssea em mulheres adultas (TsANZI et al., 2008). Dessa forma, acredita-se que, no presente estudo, os efeitos da cafeína sobre a resistência óssea à fratura podem ter sido atenuados em virtude do incremento no diâmetro da diáfise e da utilização de ratas jovens com consumo de 100\% da recomendação de cálcio, uma vez que o baixo consumo de cálcio reduz a resistência óssea à fratura em ratas (WELCH et al., 2008).

Resultado importante do presente estudo foi que o programa de saltos verticais na água aumentou o diâmetro da diáfise femoral, independentemente da suplementação (Tabela 2). Estudos anteriores mostraram resultados similares aos deste para diâmetro da diáfise em resposta a corrida voluntária, corrida em esteira e saltos em profundidade em ratos e ratas (SHIGA et al., 2003; HUANG et al., 2002; Honda et al., 2003). Assim, os achados do presente estudo com saltos verticais na água corroboram aqueles reportados com saltos em profundidade fora da água (Honda et al., 2003; WELCH et al., 2008) e suportam a ideia de que o exercício de saltos produz estímulos osteogênicos que resultam em maior deposição óssea.

Todavia, observou-se no presente estudo que a excreção urinária de cálcio foi maior no grupo CCE, quando comparada à do grupo CCS (Tabela 3). Isso indica que o programa de exercício elevou a excreção de cálcio. Essa elevação da excreção de cálcio poderia ser explicada pelo aumento dos níveis de paratormônio (PTH), que reduziria a reabsorção de cálcio nos túbulos renais. Em estudo anterior do nosso laboratório (Franco et al., 2007), com o mesmo modelo de exercício, observamos que a concentração de lactato sanguíneo se elevou do repouso para o pós-exercício (de 2,7। \pm 0,59 para 9,24 \pm I,83 mmol/L respectivamente). $\bigcirc$ exercício, ao aumentar a acidose e o lactato, promove aumento dos níveis de paratormônio (PTH) (BouASSIDA et al., 2006). Entretanto, futuros estudos são necessários para verificar se o programa de saltos verticais na água provoca aumento do PTH.

Mais importante, o programa de saltos verticais na água utilizado no presente estudo elevou também a resistência óssea à fratura nas ratas (Tabela 3), independentemente da suplementação. Esse resultado pode ser explicado pelo aumento no diâmetro da diáfise e pela tendência ao aumento da massa óssea, que resulta em maior área da secção transversal óssea e consequente aumento de sua resistência à fratura. Estudos prévios demonstraram que programas de exercício como corrida em esteira e saltos em profundidade fora da água aumentaram a 
resistência óssea à fratura em ratos e ratas (HUANG et al., 2003; WELCH et al., 2008). Um dos possíveis mecanismos para a maior resistência à fratura é a maior taxa de deformação da matriz óssea em resposta ao exercício. Esse efeito aumenta o fluido no sistema de rede lacunar-canalicular, que, por sua vez, estimula os osteócitos a desencadear uma cascata de eventos celulares, potencializando, assim, o efeito osteogênico (TURner; Robling, 2005). Outra possibilidade é que a maior capacidade contrátil muscular, em resposta ao exercício, pode elevar o estímulo osteogênico por aumentar a força de tração sobre o osso. Na unidade funcional músculo-esquelética, a massa, o tamanho e a resistência óssea são alterados em função da maior força produzida sobre o osso pela contração muscular (DALY, et al., 2004). Em trabalho anterior de nosso grupo (Franco et al., 2007), observouse que o modelo de saltos verticais na água aumentou o conteúdo de proteína na massa magra de ratos. Esse aumento poderia elevar a capacidade de contração muscular, que resultaria em maior estímulo osteogênico e, consequentemente, maior resistência à fratura óssea.

Por fim, o presente estudo apresenta algumas limitações, tais como a falta da mensuração dos níveis de GH e de PTH, além da densidade e conteúdo mineral ósseo e análise morfométrica do fêmur. Essas medidas poderiam auxiliar na explicação dos achados deste estudo. Para futuras pesquisas, o modelo de saltos verticais na água poderia ser usado em ratas com idades mais avançadas ou ovariectomizadas, com e sem consumo da recomendação dietética de cálcio.

\section{CONCLUSÃO}

Concluiu-se que, apesar de a suplementação com alta dosagem de cafeína prejudicar o metabolismo de cálcio, essa alteração não foi suficiente para interferir na resistência femoral à fratura em ratas jovens. $O$ programa de saltos verticais na água, por sua vez, aumentou a resistência óssea à fratura nesses animais. Esses resultados acrescentam informações importantes ao conhecimento acerca da ingestão de cafeína e da prática de atividade física para a saúde óssea. 
Supplementation with high dosage of caffeine do not affect bone breaking force in female rats submitted to a vertical jump training

ABSTRACT: Objective: to test the effects of high dosage of caffeine on the bone breaking force of young female rats submitted to vertical jumping training. Methods: young female rats were divided into 4 groups ( $2 \times 2$ factorial, Caffeine and Exercise). Caffeine groups ingested 3 doses of caffeine ( $10 \mathrm{mg} / 100 \mathrm{~g}$ bw) weekly. Exercise groups performed vertical jumps in water, 5 days/week, for 6 weeks. Urinary calcium, femur's diameter, mass and breaking force were assessed. Results: caffeine and exercise increased the loss of calcium. Caffeine increased diameter and reduced femur mass, but did not affect its breaking force. Exercise increased bone's diameter and bone breaking force. Conclusion: caffeine does not impair bone breaking force in young female rats while vertical jumping enhances bone strength.

KEY WORDS: Exercise; bone health.

\section{Suplementación con alta cantidad de cafeína no afecta la resistencia sobre la fractura ósea en ratas sometidas al entrenamiento de saltos verticales}

RESUMEN: Objetivo: testar los efectos de la suplementación con alta cantidad de cafeína sobre la resistencia ósea a la fractura en ratas jóvenes sometidas al entrenamiento de saltos verticales. Métodos: ratas jóvenes fueron puestas en 4 grupos (Factorial 2 × 2, Cafeína e Ejercicio). Los grupos cafeína recibieron 3 dosis ( 10 mg/l 00 g p.c.) a la semana. Los grupos ejercicio realizaron saltos verticales dentro de la agua, 5 días/semana, durante 6 semanas. Se evaluaron el calcio urinario, el diámetro, masa y resistencia a la fractura del fémur. Resultados: cafeína e ejercicio aumentaron la pérdida de calcio. Cafeína aumentó el diámetro además de disminuir la masa ósea, pero no afectó la resistencia ósea. Ejercicio aumentó el diámetro y la resistencia ósea. Conclusión: cafeína no perjudica la resistencia ósea en ratas jóvenes pero saltos verticales fortalecen los huesos.

PALABRAS CLAVES: Ejercicio; salud ósea.

\section{REFERÊNCIAS}

ALTIMARI, L. R.; MORAES, A. C.; TIRAPEGUI, J.; MOREAU, R. L. M. Cafeína e performance em exercícios anaeróbios. Revista Brasileira de Ciências Farmacêuticas, São Paulo, v. 42, n. I, p. 17-27, 2006a.

ALTIMARI, L. R.; MELO, J. C.; TRINDADE, M. C. C.; CYRINO, E. S.; TIRAPEGUI, J. Cafeína e exercício físico aeróbio. Nutrire: Revista da Sociedade Brasileira de Alimentação e Nutrição, São Paulo, v. 31, n. I, p. 79-96, 2006 b.

ASHIZAWA, N.; FUJIMURA, R.; JOKUYAMA, K.; SUZUKI, M. A bout of resistance exercise increases urinary calcium independently of osteoclastic activation in men. Journal of Applied Physiology, Bethesda, v. 83, n. 4, p. 1.159-1.163, 1997. 
ASTORINO, T. A.; ROHMANN, R. L.; FIRTH, K. Effect of caffeine ingestion on one repetition maximum muscular strenght. European Journal of Applied Physiology, Heidelberg, v. 102 , p. 127-132, 2008.

BONNET, N.; BEAUPIED, H.; VICO, L. et al. Combined effects of exercise and propranolol on bone tissue in ovariectomized rats. Journal of Bone and Mineral Research, Baltimore, v. 22, n. 4, p. 578-588, 2007.

BOUASSIDA, A.; LATIRI, I.; BOUASSIDA, S. et al. Parathyroid hormone and physical exercise: a brief review. Journal of Sports Science and Medicine, Bursa, v. 5, n. 4-5, p. 367-374, 2006.

BRUCE, C. R.; ANDERSON, M. E.; FRASER, S. F. et al. Enhancement of 2000-m rowing performance after caffeine ingestion. Medicine and Science in Sports and Exercise, Madison, v. 32, n. II, p. I.958-1.963, 2000.

CLOZEL, M.; BRANCHAUD, C. L.; TANNENBAUM, G. S. et al. Effect of caffeine on thyroid and pituitary function in newborn rats. Pediatric Research, The Woodlands, v. 17, n. 7, p. 592-595, 1983.

DALY, R. M.; SAXON, L.; TURNER, C. H. et al. The relationship between muscle size and bone geometry during growth and in response to exercise. Bone, Boston, v. 34, n. 2, p. $281-287,2004$.

DEW, T. P.; DAY, A. J.; MORGAN, M. R. A. Bone mineral density, polyphenols and caffeine: a reassessment. Nutrition Research Reviews, Dublin, v. 20, p. 89-105, 2007.

DUNCAN, M. J.; LYONS, M.; HANKEY, J. Placebo effects of caffeine on short-term resistance exercise to failure. International Journal of Sports Physiology and Performance, La Crosse, v. 4, n. 2, p. 244-253, 2009.

FIMLAND, M. S.; HELGERUD, J.; KNUFSEN, A. et al. No effect of prior caffeine ingestion on neuromuscular recovery after maximal fatiguing contractions. European Journal of Applied Physiology, Bethesda, v. 108, p. 123-130, 2010.

FRANCO, F. S. C.; NATALI, A. J.; COSTA, N. M. B. et al. Efeitos da suplementação de creatina e do treinamento de potência sobre a performance e a massa corporal magra de ratos. Revista Brasileira de Medicina do Esporte, São Paulo, v. I3, n. 5, p. 297-302, 2007.

GREER, F; MCLEAN, C.; GRAHAM, T. E. Caffeine, performance, and metabolism during repeated Wingate exercise tests. Journal of Applied Physiology, Bethesda, v. 85, n. 4, p. I.502I.508, 1998.

HEANEY, R. P. Effects of caffeine on bone and the calcium economy. Food and Chemical Toxicology, Richmond, v. 40, n. 9, p. I.263-1.270, 2002.

HENRY, R. J.; CANNON, D. C.; WINKELMAN, J. W. Clinical chemistry and technics. 2. ed. New York: Harper \& Row, 1974. 
HESPEL, P.; EIJNDE, B. O.; VAN LEEMPUTTE, M. et al. Oral creatine supplementation facilitates the rehabilitation of disuse atrophy and alters the expression of muscle myogenic factors in humans. Journal of Physiology, Cambridge, v. I5, n. 536, p. 625-633, 200 I.

HOCHBERG, Z.; HERTZ, P.; BENDERLY, A. Caffeine stimulates growth hormone secretion by cultured rat pituitary cells. Journal of Endocrinological Investigation, Milano, v. 7, n. I, p. 59-60, 1984.

HONDA, A.; SOGO, N.; NAGASAWA, S. et al. High-impact exercise strengthens bone in osteopenic ovariectomized rats with the same outcome as Sham rats. Journal of Applied Physiology, Bethesda, v. 95, n. 3, p. 1.032-1.037, 2003.

HUANG, T. H.; YANG, R. S.; HSIEH, S. S.; LIU, S. H. Effects of caffeine and exercise on the development of bone: a densitometric and histomorphometric study in young wistar rats. Bone, Boston, v. 30, n. I, p. 293-299, 2002.

HUANG, T. H; LIN, S. C.; CHANG, F. L. et al. Effects of different exercise modes on mineralization, structure, and biomechanical properties of growing bone. Journal of Applied Physiology, Bethesda, v. 95, n. I, p. 300-307, 2003.

HUANG, T. H; LIN, S. C.; CHANG, F. L. et al. Endurance treadmill running training benefits the biomaterial quality of bone in growing male Wistar rats. Journal of Bone and Mineral Metabolism, Baltimore, v. 26, n. 4, p. 350-357, 2008.

IWAMOTO, M.; ONISHI, A.; FUCHIMOTO, D. et al. Effects of caffeine treatment on aged porcine oocytes: parthenogenetic activation ability, chromosome condensation and development to the blastocyst stage after somatic cell nuclear transfer. Zygote, Naples, v. I3, n. 4, p. 335-345, 2005.

JAMES, R. S.; WILSON R. S.; ASKEW, G. N. Effects of caffeine on mouse skeletal muscle power output during recovery from fatigue. Journal of Applied Physiology, Bethesda, v. 96, n. 2, p. 545-552, 2004.

KALMAR, J. M.; CAFARELLI, E. Effects of caffeine on neuromuscular function. Journal of Applied Physiology, Bethesda, v. 87, n. 2, p. 801-808, 1999.

LINDEN, C.; AHLBORG, A. G.; BESJAKOV, J.; GARDSELL, P.; KARLSSON, M. K. A school curriculum-based exercise program increases bone mineral accrual and bone size in prepubertal girls: two-year data from the pediatric osteoporosis prevention (POP) study. Journal of Bone and Mineral Research, Baltimore, v. 2 I, n. 6, p. 829-835, 2006.

MAGKOS, F.; KAVOURAS, S. A. Caffeine Use in sports, pharmacokinetics in man, and cellular mechanisms of action. Critical Reviews in Food Science and Nutrition, Amherst, v. 45, n. 7-8, p. 535-562, 2005. 
MASSEY, L. K.; SUTTON, R. A. Acute caffeine effects on urine composition and calcium kidney stone risk in calcium stone formers. Journal of Urology, Charlottesville, v. 172, n. 2, p. 555-558, 2004.

OLIVEIRA, C. A. M.; ROGATTO, G. P.; LUCIANO, E. Efeitos do treinamento físico de alta intensidade sobre os leucócitos de ratos diabéticos. Revista Brasileira de Medicina do Esporte, São Paulo, v. 8, n. 6, p. 219-224, 2002.

RAPURI, P. B.; GALLANGHER, J. C.; KYNYAMU, H. K.; RYSCHON, K. L. Caffeine intake increases the rate of bone loss in elderly women and interacts with vitamin $\mathrm{D}$ receptor genotypes. The American Journal of Clinical Nutrition, Houston, v. 74, n. 5, p. 697-700, 2001.

ROBLING, A. G.; CASTILLO, A. B.; TURNER, C. H. Biomechanical and molecular regulation of bone remodeling. Annual Review of Biomedical Engineering, Palo Alto, v. 8, p. 455-498, 2006.

SHIGA, K.; HARA, H.; OKANO, G. et al. Ingestion of difructose anhydride III and voluntary running exercise independently increase femoral and tibial bone mineral density and bone strength with increasing calcium absorption in rats. The Journal of Nutrition, Bethesda, v. I33, n. 12, p. 4.207-4.21।, 2003.

SMITH, A.; SUTHERLAND, D.; CHRISTOPHER, G. Effects of repeated doses of caffeine on mood and performance of alert and fatigued volunteers. Journal of Psychopharmacology, London, v. 19, n. 6, p. 620-626, 2005.

SPINDEL, E.; ARNOLD, M.; CUSACK, B.; WURTMAN, R. J. Effects of caffeine on anterior pituitary and thyroid function in the rat. Journal of Pharmacology and Experimental Therapeutics, Bethesda, v. 214 , n. I, p. 58-62, 1980.

TOURNIS, S.; MICHPOULOU, E.; FATOUROS, I. G. et al. Effect of rhythmic gymnastics on volumetric bone mineral density and bone geometry in premenarcheal female athletes and controls. The Journal of Clinical Endocrinology and Metabolism, Chevy Chase, v. 95, n. 6, p. $1-8,2010$.

TSANZI, E.; LIGHT, H. R.; TOU, J. C. The effect of feeding different sugar-sweetened beverages to growing female Sprague-Dawley rats on bone mass and strength. Bone, Boston, v. 42, n. 5, p. 960-968, 2008.

TURNER, C. H.; ROBLING, A. G. Mechanisms by which exercise improves bone strength. Journal of Bone and Mineral Metabolism, Baltimore, v. 23, p. 16-22, 2005.

VAN THUYNE, W.; ROELS, K.; DELBEKE, F. T. Distribution of caffeine levels in urine in different sports in relation to doping control. International Journal of Sports Medicine, Stuttgart, v. 26, p. 7|4-7|8, 2005. 
WELCH, J. M.; TURNER, CH; DEVAREDDY, L. et al. High impact exercise is more beneficial than dietary calcium for building bone strength in the growing rat skeleton. Bone, Boston, v. 42, n. 4, p. 660-668, 2008.

WETMORE, C. M.; ICHIKAWA, L.; LACROIX, A. Z. et al. Association between caffeine intake and bone mass among young women: potential effect modification by depot medroxyprogesterone acetate use. Osteoporosis International, Heidelberg, v. 19, n. 4, p. 519-527, 2008.

ZHOU, Y.; ZHU, Z. L.; GUAN X. X. et al. Reciprocal roles between caffeine and estrogen on bone via differently regulating CAMP/PKA pathway: the possible mechanism for caffeineinduced osteoporosis in women and estrogen's antagonistic effects. Medical Hypotheses, Birmingham, v. 73, p. 83-85, 2009.

Recebido: 29 jun. 2009

Aprovado: 29 mar. 2010

Endereço para correspondência:

Antônio José Natali

Programa de Pós-Graduação em Educação Física Universidade Federal de Viçosa - Departamento de Educação Física Avenida PH Rolfs, s/n - Campus Universitário Viçosa-MG CEP 36570-000 